\title{
Vitamin D status in Saudi school children based on knowledge
}

\author{
Yousef Al-Saleh ${ }^{1,2}$, Nasser M Al-Daghri ${ }^{2,3^{*}}$, Nasiruddin Khan ${ }^{2,3}$, Hanan Alfawaz ${ }^{2,4}$, Abdulaziz M Al-Othman ${ }^{2,5}$, \\ Majed S Alokail ${ }^{1,2}$ and George P Chrousos ${ }^{2,6}$
}

\begin{abstract}
Background: The prevalence of vitamin D deficiency in the kingdom of Saudi Arabia is rising unexpectedly in every age group. Apart from several risk factors, the lack of awareness is posing a serious threat for low vitamin D levels in children as well. The aim of our study was to compare the knowledge and status of vitamin D in Saudi school children.

Methods: Saudi students, 1188 boys (15.1 \pm 2.2 years) and 1038 girls (15.1 \pm 2.0 years), were recruited and a pre-designed questionnaire with regards to knowledge about vitamin $\mathrm{D}$ was administered. Blood samples were collected and serum 25hydroxyvitamin D $(25(\mathrm{OH}) \mathrm{D}$ was measured.

Results: A significantly higher percentage of boys answered correctly than girls regarding knowledge questions as sun exposure $(p=0.002$, and 0.011$)$, breastfeeding $(p<0.001)$ and diseases $(p<0.001)$. The percentage of girls was significantly higher who thought that fruits and vegetables are not rich sources of vitamin D (24.7\% girls vs. $15.4 \%$ boys; $p<0.001$ and $29.6 \%$ girls vs. $20.9 \%$ boys $p<0.001$ ), respectively. Boys had a higher prevalence and frequency of sun exposure than girls ( $p<0.001$ for both). Girls showed a significantly higher percentage of sunscreen use and full covering during sun exposure ( $p=0.001$ for both).Vitamin $D$ deficiency was significantly higher in girls than boys (47.0\% versus 19.4.0\%; $p<0.001)$. Vitamin $D$ status in boys was significantly higher than girls $(p<0.001)$. In girls, those who answered correctly about vitamin D related disease $(p=0.03)$ and sources $(p=0.015)$, demonstrated significantly higher vitamin D levels.

Conclusions: The awareness of vitamin D and sunlight in children needs to be improved by provision of trained physicians and school teachers. Creating more areas where girls can uncover freely during routine works and outdoor activities will help increase their vitamin D levels.
\end{abstract}

Keywords: Hypovitaminosis D, Awareness, Sunlight, Physicians, Teacher, Gender

\section{Background}

The worldwide increased prevalence of vitamin D deficiency in both children and adults [1] has been related to various factors, including exposure time of skin to ultraviolet radiation [2], skin pigmentation and vitamin D intake [3]. Moreover, vitamin D receptor (VDR) polymorphisms [4], obesity and social status [5-7] could also play important roles in modulating the levels of circulating

\footnotetext{
* Correspondence: aldaghri2011@gmail.com

${ }^{2}$ Prince Mutaib Bin Abdullah Chair on Osteoporosis, Biochemistry

Department, College of Science, King Saud University, PO Box, 2455, Riyadh

11451, Kingdom of Saudi Arabia

${ }^{3}$ Biomarkers Research Program Biochemistry Department, College of Science, King Saud University, Riyadh, Saudi Arabia

Full list of author information is available at the end of the article
}

vitamin D. Despite sufficient sunlight throughout the year, the kingdom of Saudi Arabia (KSA) is facing a common problem of vitamin $\mathrm{D}$ deficiency in both children and adults [8-10].

A recent study amongst Saudi locals and expatriates revealed higher vitamin $D$ levels during winter months than in the summer [11]. The reason for this unexpected trend in the summer was the avoidance of sunlight to prevent from scorching heat effects on skin and health. In addition, girls are more vitamin D deficient as they receive little or no sunlight due to the covering of their bodies with dark veils for cultural and religious reasons. A recent study from our group in 331 Saudi children aged 6-17 years (153 boys and 178 girls) 
demonstrated that all subjects were vitamin $\mathrm{D}$ deficient (serum 25- $(\mathrm{OH})$ vitamin $\mathrm{D}$ ) with the majority being moderately deficient (71.6\%) [12].

It is now becoming clear that apart from several risk factors, the lack of awareness is also posing a serious threat for low vitamin D levels almost in every age group. For instance, the Australian surveys showed a limited awareness and understanding about vitamin D in the adults [13]. There are studies from different parts of Saudi Arabia demonstrating that a limited knowledge and awareness about vitamin D could be a potential reason for vitamin D deficiency among female students $[14,15]$. Hence, the understanding and knowledge of the importance and role of vitamin D in one's normal daily life is a basic need and the general community, especially children, should be aware of this.

There are several studies from Saudi Arabia regarding knowledge about vitamin D and its deficiency. However, these either included adults or only female students as participants. On the contrary, this study focused on school children, both boys and girls, comparing their knowledge about the role and importance of vitamin $\mathrm{D}$ and its deficiency. In addition, the correlation of such knowledge and vitamin D status in school children was also examined.

\section{Methods}

\section{Subjects and data collection}

A total of 2226 apparently healthy Saudi students were recruited from randomly selected public secondary schools within Riyadh, Saudi Arabia, and consisted of 1188 boys (mean age, $15.1 \pm 2.2$ years) and 1038 girls $(15.1 \pm 2.0)$. Written informed consents from the parents of adolescents were obtained prior to inclusion. Subjects with chronic conditions such as asthma and type 1 diabetes mellitus, those needing acute medical attention, use medications known to affect body weight (such as steroids) and those taking calcium and multivitamin supplements, were excluded from the study. Ethical approval was obtained from the Ethics Committee of the College of Science Research Center, King Saud University, Riyadh, Saudi Arabia. Approval to conduct the study and access to students were also obtained from the Ministry of Education. A pre-designed and approved questionnaire, which included information on socio-demographics, polar questions (yes or no questions) with regards to knowledge about vitamin $\mathrm{D}$ and vitamin $\mathrm{D}$-associated diseases were administered to all subjects along with multiple choice questions about sunshine exposure and duration.

\section{Anthropometrics}

Physical examination was carried out by the school attending physician and nurse during break time to avoid class disruption. Weight and height were recorded to the nearest $0.2 \mathrm{~kg}$ and $0.5 \mathrm{~cm}$, respectively, using an appropriate international standard scale (Digital Pearson Scale, ADAM Equipment Inc., USA). Waist circumferences were measured using non-stretchable tape. Definition of BMI was based on the cutoffs proposed by Cole and colleagues [16].

\section{Vitamin $\mathrm{D}$ status analysis}

Blood samples were collected by the school physician and nurse immediately after anthropometrics. Serum 25(OH)D was measured using COBAS e-411 automated analyzer (Roche Diagnostics, Indianapolis, IN, USA) in a DEQAS (Vitamin D External Quality Assessment Scheme) accredited laboratory (Prince Mutaib Chair for Biomarkers of Osteoporosis, Biochemistry Department, College of Science, King Saud University, Riyadh, Saudi Arabia). The various states of vitamin D status were defined as: deficient $(<25 \mathrm{nmol} / \mathrm{L})$; insufficient $(25-50 \mathrm{nmol} / \mathrm{L})$; sufficient $(50-75 \mathrm{nmol} / \mathrm{L})$ and desirable $(>75 \mathrm{nmol} / \mathrm{L})$. Subjects diagnosed with vitamin D deficiency were subsequently referred to the school physician for further guidance.

\section{Statistical analysis}

Data was analyzed using SPSS version 16.0 (SPSS, Chicago, IL, USA). Frequencies were presented as percentages (\%) and continuous variables were presented as mean \pm standard deviation. Chi-Square test was done to compare frequencies and independent Student-test for normally distributed continuous variables. Significance was set at $\mathrm{p}$-value $<0.05$.

\section{Results}

Vitamin D awareness

Table 1 highlights the demographics of boys and girls, as well as their knowledge on vitamin D and vitamin D-related diseases and sun exposure. There is a significant difference in skin color distribution among subjects, with girls having a higher prevalence of "fair-toned" skin than boys ( $p$ <.001). Housing-wise, the majority of the students lived in villas, with girls having a modestly higher prevalence of villa residency than boys $(\mathrm{p}<0.001)$. With regards to vitamin $\mathrm{D}$ knowledge, there was a significantly higher percentage of boys answering "yes" than girls in 5 out of 12 questions, 4 of which was correct [30 minute sun exposure provides enough calcium and vitamin D, about breastfeeding, and vitamin $\mathrm{D}$ deficiency leads to rickets in children; p-values $0.002,0.0110 .001$, and 0.001 respectively]. On the other hand, while the majority of both boys and girls thought that fruits and vegetables are rich in vitamin $\mathrm{D}$, a significantly higher percentage of girls got it correct (24.7\% girls versus $15.4 \%$ boys; p-value $<0.001$ and $29.6 \%$ girls versus $20.9 \%$ boys; $\mathrm{p}$-values $<0.001$, not shown in table). Worthy to note is 
Table 1 Demographics and vitamin $D$ awareness of subjects

\begin{tabular}{|c|c|c|c|}
\hline Parameters & Boys & Girls & P-value \\
\hline $\bar{N}$ & 1188 & \multicolumn{2}{|c|}{1038} \\
\hline Age (years) & \multirow[t]{2}{*}{$15.1 \pm 2.2$} & \multicolumn{2}{|c|}{$15.1 \pm 2.0 \mathrm{NS}$} \\
\hline \multicolumn{3}{|l|}{ Skin Color } & \\
\hline Fair & 31.4 & 39.1 & $<0.001$ \\
\hline Light Brown & 60.1 & 56.4 & \\
\hline Dark Brown & 7.8 & 4.4 & \\
\hline Black & 0.7 & 0.1 & \\
\hline \multicolumn{4}{|l|}{ Housing } \\
\hline Apartment & 33.5 & 25.2 & $<0.001$ \\
\hline Villa & 63.4 & 69.3 & \\
\hline Public House & 3.0 & 5.5 & \\
\hline \multicolumn{4}{|l|}{ Education } \\
\hline Elementary & 5.9 & 2.9 & NS \\
\hline Primary & 55.8 & 54.5 & \\
\hline Secondary & 38.1 & 42.3 & \\
\hline College/Post-Graduate & 0.3 & 0.3 & \\
\hline $\begin{array}{l}\text { Do you take vitamin D } \\
\text { supplements? }\end{array}$ & 45.7 & 41.9 & NS \\
\hline \multicolumn{4}{|l|}{ Vitamin D Knowledge* } \\
\hline $\begin{array}{l}\text { Have you heard about vitamin } \\
\text { D sources in school? }\end{array}$ & 45.7 & 47.9 & NS \\
\hline $\begin{array}{l}\text { Have you heard about vitamin D } \\
\text { sources in primary care centers? }\end{array}$ & 27.5 & 32.1 & 0.018 \\
\hline $\begin{array}{l}\text { Does } 30 \text { min exposure to sun } \\
\text { provide enough calcium? }\end{array}$ & 63.9 & 57.8 & 0.002 \\
\hline $\begin{array}{l}\text { Does } 30 \text { min exposure to sun } \\
\text { provide enough vitamin } D ?\end{array}$ & 76.5 & 72.1 & 0.011 \\
\hline Are vegetables rich in vitamin D? & 79.1 & 70.4 & $<0.001$ \\
\hline Are fruits rich in vitamin D? & 84.6 & 75.3 & $<0.001$ \\
\hline $\begin{array}{l}\text { Does breastfeeding contain } \\
\text { enough vitamin } D \text { ? }\end{array}$ & 81.5 & 71.7 & $<0.001$ \\
\hline $\begin{array}{l}\text { Is vitamin D important in calcium } \\
\text { absorption? }\end{array}$ & 84.4 & 83.8 & NS \\
\hline $\begin{array}{l}\text { Does vitamin D deficiency lead } \\
\text { to rickets in children? }\end{array}$ & 90.9 & 85.6 & $<0.001$ \\
\hline $\begin{array}{l}\text { Does vitamin D deficiency lead } \\
\text { to osteomalacia? }\end{array}$ & 85.3 & 84.1 & NS \\
\hline $\begin{array}{l}\text { Does vitamin D deficiency lead } \\
\text { to osteoporosis? }\end{array}$ & 91.4 & 89.7 & NS \\
\hline \multicolumn{4}{|l|}{$\begin{array}{l}\text { What is the recommended dose } \\
\text { for vitamin } D \text { ? }\end{array}$} \\
\hline $40-80 \mathrm{IU}$ & 42.0 & 41.6 & 0.016 \\
\hline $400-800 \mathrm{IU}$ & 51.7 & 55.0 & \\
\hline $4000-8000 \mathrm{IU}$ & 6.4 & 3.4 & \\
\hline \multicolumn{4}{|l|}{ Sunlight Exposure } \\
\hline Do you expose yourself to sunlight? & 77.5 & 54.3 & $<0.001$ \\
\hline
\end{tabular}

Table 1 Demographics and vitamin $D$ awareness of subjects (Continued)

\begin{tabular}{|c|c|c|c|}
\hline One to three times daily & 55.7 & 41.2 & $<0.001$ \\
\hline One to two times per week & 31.3 & 33.2 & \\
\hline Three to five times per week & 13.1 & 25.6 & \\
\hline \multicolumn{4}{|l|}{ Time of sunlight exposure } \\
\hline Sunrise to $10 \mathrm{am}$ & 37.3 & 38.1 & NS \\
\hline $10-a m-3$ pm & 35.6 & 35.7 & \\
\hline After 3 pm & 27.2 & 26.2 & \\
\hline $\begin{array}{l}\text { Do you expose yourself to } \\
\text { sunlight all-year through? }\end{array}$ & 62.9 & 41.8 & $<0.001$ \\
\hline $\begin{array}{l}\text { Do you expose yourself to } \\
\text { sunlight on certain seasons? }\end{array}$ & 38.5 & 45.1 & 0.001 \\
\hline $\begin{array}{l}\text { Are you fully covered during } \\
\text { sun exposure? }\end{array}$ & 22.5 & 28.3 & 0.001 \\
\hline Do you use sunscreen? & 3.0 & 7.9 & 0.001 \\
\hline
\end{tabular}

*Percentage of all responses corresponds to "YES", NS: non-significant.

the low percentage of both boys and girls having heard of vitamin $\mathrm{D}$ sources in both schools and primary care centers, which means that knowledge on vitamin $\mathrm{D}$ and its sources were probably acquired elsewhere (e.g. parents, media). As for sun exposure, boys had a higher prevalence of sun exposure than girls as well as increased frequency (p-values 0.001, for both). Consequently and as expected, girls had a significantly higher percentage of sunscreen use and full covering during sun exposure (p-values 0.001 and 0.02 , for both) (Table 1 ).

\section{Vitamin D status}

Vitamin D deficiency was significantly higher in girls than boys $(47.0 \%$ versus $19.4 \%$; $\mathrm{p}<0.001)$, with less than $3 \%$ of the entire cohort achieving desirable vitamin D levels and majority falling under the vitamin $\mathrm{D}$ insufficient category (Table 2). Accordingly, serum mean vitamin $D$ level in boys was significantly higher than girls ( $39.0 \pm 0.6$ versus $29.5 \pm 0.6 \mathrm{nmol} / \mathrm{l}$, respectively).

\section{Mean vitamin D levels and vitamin D knowledge}

Vitamin D status was compared in 8 out of the 12 polar questions relating to vitamin $\mathrm{D}$ knowledge (Table 3). Both boys and girls who answered "Yes" to the question "Have you heard about vitamin D sources in primary care centers ?" have a significantly higher vitamin D levels as compared to "No" (p-values 0.03 and 0.05 , respectively). In girls, mean vitamin D levels were significantly higher in those who answered "No" as to "whether vegetables are rich in vitamin D" (p-values 0.015) as compared to those who responded "Yes". Similarly, significantly higher mean vitamin D levels (p-values 0.03 ) were observed in girls responding correctly to "Does vitamin D lead to osteoporosis" as compared to "No". 
Table 2 Biochemical characteristics of the subjects (children)

\begin{tabular}{llll}
\hline Parameter & Boys & Girls & P-value \\
\hline $\mathrm{N}$ & 1188 & 1038 & \\
Vitamin D Status & & & \\
Deficient (\%) & 19.4 & 47.0 & $<0.001$ \\
Insufficient (\%) & 59.6 & 45.5 & \\
Sufficient (\%) & 17.2 & 4.7 & \\
Desirable (\%) & 3.9 & 2.7 & \\
BMl (kg/m $\left.{ }^{2}\right)$ & $22.9 \pm 0.2$ & $23.0 \pm 0.2$ & NS \\
25-OH Vitamin D (nmol/l) & $39.0 \pm 0.6$ & $29.5 \pm 0.6$ & $<0.001$ \\
\hline
\end{tabular}

Note: Data presented as percentage (\%) for frequencies; mean \pm standard error for continuous variables; $p$-value significant at $<0.05$, NS: non-significant.

\section{Discussion}

The present study assessed vitamin D status in Saudi children searching for a possible correlation between vitamin $\mathrm{D}$ status and knowledge. We observed a significantly higher vitamin D deficiency in girls as compared to boys supporting various studies [13-15].

\section{Vitamin D awareness}

This study demonstrates the lack of basic knowledge about vitamin $\mathrm{D}$ which was found to be more prevalent among girls than boys. Boys responded with more correct answers than girls (5 out of 12 questions, 4 of which are correct) regarding vitamin D. Gaps in basic knowledge around vitamin D and its benefits became apparent in this study. As described earlier, Christie et al. [14] demonstrated limited knowledge of female students (20 and 25 years) about vitamin D and vitamin D deficiency. In addition, Siddiqui et al. also showed a lack of awareness about the role of vitamin D among school girls (12-15 years) [15]. Our study supported the findings of Siddiqui et al. showing more lack of knowledge in girls. The lack of basic knowledge about sources of vitamin D in both boys and girls was also observed as they responded "yes" for the question "Are fruits rich in vitamin D?" which was incorrect. However, the percentage of girls $(24.8 \%)$ was significantly higher than boys (15\%) who gave correct answer responding "No". The above results (Table 1) also correspond to the results described in Table 3 in which the girls responding correctly (No instead of yes) in the question "Are fruits rich in vitamin D?" demonstrated higher serum 25-OH vitamin D level than boys.

\section{Sources of information about vitamin D}

Principally, in children, the primary source of basic knowledge about healthy diet (including minerals and vitamins) is obtained either from the schools or from primary care centers, although this was not the case in our study. The majority of the participants got the information about vitamin D from other sources like their parents and media. There are studies demonstrating the lack of nutritional knowledge in health care professionals from different countries rating from very poor to weak $[17,18]$. A recent study from United Arab Emirates demonstrated gaps in the knowledge as well as lack of management skills of physicians regarding bone health [19]. Another study from Qatar performed by Daradkeh et al. rated the nutritional knowledge in physicians as: very good (19\%), moderate $(60 \%)$, and poor $(21 \%)$, indicating the need for nutrition to be included as an essential part for medical education [20].

Indeed, the few studies that have looked at vitamin D knowledge have found staggeringly low rates of awareness [14,21,22]. For example, a qualitative study conducted in Saudi Arabia found only minimal awareness of vitamin $\mathrm{D}$ knowledge, including where it comes from and what it does for health [14]. According to Khalsa, many health-care professionals are not fully aware of the benefits of vitamin D to public health [23]. Al-Numair et al. demonstrated that in Saudi Arabia, 75\% of the physicians described their knowledge of nutrition as "poor" [24]. In addition, the majority of the physicians (81\%) working in the Ministry of Health $(\mathrm{MOH})$ primary

Table 3 Mean vitamin D levels based on general knowledge about vitamin D among schoolboys and girls

\begin{tabular}{|c|c|c|c|c|c|c|}
\hline & \multicolumn{3}{|l|}{ BOYS } & \multicolumn{3}{|l|}{ GIRLS } \\
\hline & Yes & No & P-value & Yes & No & P-value \\
\hline Have you heard about vitamin D in school? & $39.3 \pm 0.9$ & $38.1 \pm 0.9$ & NS & $29.8 \pm 0.9$ & $29.2 \pm 0.7$ & NS \\
\hline Have you heard about vitamin D sources in primary care centers & $41.1 \pm 1.6$ & $37.4 \pm 0.6$ & 0.03 & $31.3 \pm 1.2$ & $28.7 \pm 0.7$ & 0.05 \\
\hline Is vitamin $\mathrm{D}$ important in calcium absorption? & $39.1 \pm 0.6$ & $38.5 \pm 1.2$ & NS & $29.6 \pm 0.6$ & $28.9 \pm 1.6$ & NS \\
\hline Does vitamin $D$ deficiency lead to rickets in children? & $38.8 \pm 0.6$ & $40.2 \pm 1.6$ & NS & $29.7 \pm 0.6$ & $28.4 \pm 1.1$ & NS \\
\hline Does vitamin $\mathrm{D}$ deficiency lead to osteomalacia in adults? & $38.8 \pm 0.6$ & $40.1 \pm 1.6$ & NS & $29.6 \pm 0.6$ & $29.3 \pm 1.2$ & NS \\
\hline Does vitamin D lead to osteoporosis? & $38.8 \pm 0.6$ & $42.2 \pm 2.2$ & NS & $29.8 \pm 0.6$ & $26.1 \pm 1.1$ & 0.03 \\
\hline Are vegetables rich in vitamin $\mathrm{D}$ ? & $38.4 \pm 0.6$ & $40.3 \pm 1.6$ & NS & $28.6 \pm 0.6$ & $31.7 \pm 1.2$ & 0.015 \\
\hline Are fruits rich in vitamin $\mathrm{D}$ ? & $39.2 \pm 0.6$ & $38.3 \pm 1.2$ & NS & $29.2 \pm 0.7$ & $30.4 \pm 1.2$ & NS \\
\hline
\end{tabular}

Note: Adjusted for the following confounding variables: age, obesity, skin color, use of sunscreen, use of vitamin D supplements, outdoor school exercise; p-value significant at $<0.05$, NS: non-significant. 
health care centers in Jeddah, Saudi Arabia, rated their nutritional knowledge as "poor" based on their responses in a validated questionnaire [25].

\section{Sunlight exposure}

The lack of sun exposure is among one of the main causes for vitamin D deficiency intake [26,27] in addition to prolonged breastfeeding and lack of a balanced diet $[28,29]$. Indeed, $80-100 \%$ of vitamin D requirement is fulfilled by exposure of the skin to sunlight [27]. In most parts of the Middle East, including Saudi Arabia, an indoor lifestyle has played a major role as an obstacle in obtaining sufficient amount of direct sun light, both in children and adults [30]. A recent study of school children from Makkah (KSA), observed higher vitamin $\mathrm{D}$ deficiency in females than males and reported the restriction of sunlight as the main cause [31]. In this study, the frequency of sunlight exposure was significantly higher in boys than girls. In Saudi Arabia, boys have more opportunity to spend most of their time outside their houses and are thus more exposed to sunlight than girls. On the other hand, girls have only few opportunities to go outside and uncover their faces or their bodies and expose themselves to the sun. The preferred outing time in the parks and malls for girls are usually in the evening, after sunset. In addition, the schools and transporting vehicles especially meant for girls are completely covered and prevent the penetration of proper sunlight.

Moreover, based on cultural traditions, concealing all of the body is considered another reason for insufficient sunlight as adapted by most Middle Eastern countries. Arab women who cover most of their skin are often vitamin D deficient [32]. The study by Siddiqui and colleagues demonstrated that women covering their body completely from head to toe limit severely sunlight exposure [15,33].

Similarly, severe vitamin D deficiency was also demonstrated in Arab-American women who wear the veil [34]. However, Sedrani and colleagues reported that, although veils could minimize exposure to sun irradiation, this was not a major contributory factor for vitamin D deficiency as a whole, in Saudi female students [35]. Supporting the results of Sedrani et al., no difference was reported in vitamin $\mathrm{D}$ level when compared among veiled and non-veiled Bangladeshi women [36]. Our present study supports the findings of Siddiqui and Hollick et al. showing vitamin D deficiency in girls due to limited sun light exposure.

A survey from Hong Kong showed that instead of having good knowledge about vitamin $\mathrm{D}$, younger (middleaged) women were ignorant of the role of sunlight in vitamin $\mathrm{D}$ production and expressed negative opinions regarding optimum exposure to sunlight [21]. In our study, the ignorance about basic concepts of vitamin D was higher in girls than boys, as evidenced by their significantly higher use of sunscreen $(\mathrm{p}<0.001)$. This lack of knowledge became more severe, when we observed that the use of sunscreen in girls was surprisingly common, in spite of knowing and responding that they were fully covered during sun exposure $(\mathrm{p}<0.02)$. So vitamin $\mathrm{D}$ deficiency in girls is higher as a result of the double negative effects of using sunscreen, as well as fully covering their body.

\section{Mean vitamin $D$ levels and vitamin $D$ knowledge}

As is evidenced from Table 3, irrespectively of gender, the mean level of vitamin D was significantly different based only at the correct responses of different questions. For instance, the group of girls who were observed with significantly higher level of vitamin D were only those who responded correctly to the question related to disease and source of vitamin D $(p=0.03$, and 0.015 , respectively). Similarly, the mean vitamin D levels was significantly higher in both boys and girls responding "yes" to the question "Have you heard about vitamin D sources in primary care centers" as compared to "No" (p-value 0.03 , and 0.05 , respectively).

\section{Conclusions}

High prevalence of vitamin D deficiency in both genders especially girls was observed in this study. The main possible reasons for this deficiency was the lack of knowledge about vitamin D (lack of sun exposure, use of sunscreen and fully covering the body during sun exposure), mostly among girls. Schools and primary care centers were not able to provide information on the importance of vitamin D in bone health, growth and development of children. Awareness of the benefits of sunlight needs to be increased by provision of specific about how often sun exposure is required, the duration, and how much of the body should be exposed for optimal vitamin D uptake. Physicians must have more nutritional knowledge and health care information about vitamin D that could be transferred easily to children's. Creating more areas where women can uncover freely may have to be part of the strategy of preventing vitamin $\mathrm{D}$ deficiency. In girls, increasing incidental sun exposure through routine, daily, outdoor activities will help increase sun exposure for vitamin D activation. Consequently, further efforts to educate children about importance and role of vitamin D through sources like media and health professionals are needed in near future.

\section{Abbreviations}

BMI: Body mass index; DEQAS: vitamin D External Quality Assessment Scheme; KSA: Kingdom of Saudi Arabia; MOH: Ministry of Health; VDR: vitamin D receptor. 


\section{Competing interests}

The authors declare that they have no competing interests.

\section{Authors' contributions}

YAS, NMA and NK contributed mainly in the design, subject recruitment, and data collection. HAF performed sample analysis, interpretation, and preparation of draft manuscript. AAO, MSA, and GPC edited the final version of the manuscript. All authors read and approved the final version of the manuscript.

\section{Acknowledgments}

The study was financially supported by the Vice Deanship of Research Chairs, King Saud University, Riyadh, Saudi Arabia.

\begin{abstract}
Author details
${ }^{1}$ King Abdulaziz Medical City, College of Medicine, King Saud Bin Abdulaziz University for Health Sciences, Riyadh 11426, Saudi Arabia. ${ }^{2}$ Prince Mutaib Bin Abdullah Chair on Osteoporosis, Biochemistry Department, College of Science, King Saud University, PO Box, 2455, Riyadh 11451, Kingdom of Saudi Arabia. ${ }^{3}$ Biomarkers Research Program Biochemistry Department, College of Science, King Saud University, Riyadh, Saudi Arabia. ${ }^{4}$ Department of Food Science and Nutrition, College of Food Science and Agriculture, King Saud University, Riyadh, Saudi Arabia. ${ }^{5}$ College of Applied Medical Sciences, King Saud University, Riyadh, Saudi Arabia. ${ }^{6}$ First Department of Pediatrics, Athens University Medical School, Athens 11527, Greece.
\end{abstract}

Received: 15 October 2014 Accepted: 24 April 2015

\section{Published online: 06 May 2015}

\section{References}

1. Bischoff-Ferrari HA, Giovannucci E, Willett WC, Dietrich T, Dawson-Hughes B. Estimation of optimal serum concentrations of 25-hydroxyvitamin $D$ for multiple health outcomes. Am J Clin Nutr. 2006;84:18-28.

2. Dawodu A, Agarwal M, Hossain M, Kochiyil J, Zayed R. Hypovitaminosis D and vitamin $\mathrm{D}$ deficiency in exclusively breast-feeding infants and their mothers in summer: a justification for vitamin D supplementation of breast-feeding infants. J Pediatr. 2003;142:169-73.

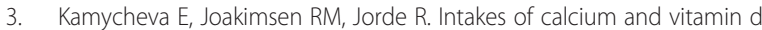
predict body mass index in the population of Northern Norway. J Nutr. 2003;133:102-6.

4. Ye WZ, Reis AF, Dubois-Laforgue D, Bellanne-Chantelot C, Timsit J, Velho G. Vitamin $D$ receptor gene polymorphisms are associated with obesity in type 2 diabetic subjects with early age of onset. Eur J Endocrinol. 2001;145:181-6.

5. Hirani V, Mosdol A, Mishra G. Predictors of 25-hydroxyvitamin D status among adults in two British national surveys. Br J Nutr. 2009;101:760-4.

6. Giovannucci E, Liu Y, Rimm EB, Hollis BW, Fuchs CS, Stampfer MJ, et al. Prospective study of predictors of vitamin D status and cancer incidence and mortality in men. J Natl Cancer Inst. 2006;98:451-9.

7. Kumar S, Mahajan G, Kumar N. Prevalence of vitamin D deficiency in apparently healthy children in north India. J Pediatr Endocrinol Metabol. 2014;27:1151-6.

8. Al-Daghri NM, Al-Attas OS, Al-Okail MS, Alkharfy KM, Al-Yousef MA, Nadhrah $\mathrm{HM}$, et al. Severe hypovitaminosis $D$ is widespread and more common in non-diabetics than diabetics in Saudi adults. Saudi Med J. 2010;31:775-80.

9. Al-Daghri NM, Al-Attas OS, Alokail MS, Alkharfy KM, Yousef M, Nadhrah HM, et al. Hypovitaminosis D and cardiometabolic risk factors among non-obese youth. Cent Eur J Med. 2010;5:752-7.

10. Elsammak MY, Al-Wosaibi AA, Al-Howeish A, Alsaeed J. Vitamin d deficiency in Saudi Arabs. Horm Metab Res. 2010;42:364-8.

11. Al-Daghri NM, Al-Attas OS, Alokail MS, Alkharfy KM, El-Kholie E, Yousef M, et al. Increased vitamin D supplementation recommended during summer season in the gulf region: a counterintuitive seasonal effect in vitamin D levels in adult, overweight and obese Middle Eastern residents. Clin Endocrinol (Oxf). 2012;76:346-50.

12. Al-Othman A, Al-Musharaf S, Al-Daghri NM, Krishnaswamy S, Yusuf DS, Alkharfy KM, et al. Effect of physical activity and sun exposure on vitamin D status of Saudi children and adolescents. BMC Pediatr. 2012;12:92.

13. Janda M, Youl P, Bolz K, Niland C, Kimlin M. Knowledge about health benefits of vitamin D in Queensland Australia. Prev Med. 2010;50:215-6.

14. Christie FT, Mason L. Knowledge, attitude and practice regarding vitamin D deficiency among female students in Saudi Arabia: a qualitative exploration. Int J Rheum Dis. 2011;14:e22-9.
15. Siddiqui AM, Kamfar HZ. Prevalence of vitamin D deficiency rickets in adolescent school girls in Western region, Saudi Arabia. Saudi Med J. 2007;28:441-4.

16. Cole TJ, Bellizzi MC, Flegal KM, Dietz WH. Establishing a standard definition for child overweight and obesity worldwide: international survey. BMJ. 2000;320:1240-3.

17. Heywood P, Wootten SA. Nutritional knowledge and attitudes towards nutrition education in medical students at Southampton University Medical School. Proc Nutr Soc. 1992;51:67A.

18. Temple NJ. Survey of nutritional knowledge of Canadian physicians. J Am Coll Nutr. 1999;18:26-9.

19. Beshyah SA, Mehri WA, Khalil AB. Osteoporosis and its management: knowledge, attitudes and practices of Physicians in United Arab Emirates. Ibnosina J Med Biomed Sci. 2013;5:270-9.

20. Daradkeh GAF, Bader KA, Singh R. The nutrition knowledge of primary care physicians in the state of Qatar. Pak J Nutr. 2012;11:781-5.

21. Kung AWC, Lee K. Knowledge of vitamin D and perceptions and attitudes toward sunlight among Chinese middle-aged and elderly women: a population survey in Hong Kong. BioMed Central Public Health. 2006;6:226.

22. Vu LH, van der Pols JC, Whiteman DC, Kimlin MG, Neale RE. Knowledge and attitudes about vitamin $\mathrm{D}$ and impact on sun protection practices among urban office workers in Brisbane, Australia. Cancer Epidemiol Biomarkers Prev. 2010;19:1784-9.

23. Khalsa $K$. The vitamin $D$ revolution, How the power of this amazing vitamin Can change your life. New York: Hay House Inc.; 2009.

24. Al-Numair KS. Nutrition knowledge of primary care physicians in Saudi Arabia. Pak J Nutr. 2004:3:344-7.

25. Al-Zahrani AM, Al-Raddadi RM. Nutritional knowledge of primary health care physicians in Jeddah, Saudi Arabia. Saudi Med J. 2009;30:284-7.

26. Holick M. Vitamin D deficiency. N Eng J Med. 2007;357:266-81.

27. Glerup H, Mikkelsen K, Poulsen L, Hass E, Overbeck S, Thomsen J, et al. Commonly recommended daily intake of vitamin $D$ is not sufficient if sunlight exposure is limited. J Intern Med. 2000;247:260-8.

28. Fuleihan G. Vitamin D deficiency in the Middle East and its health consequences for children and adults. Clinic Rev Bone Miner Metab. 2009;7:77-93.

29. Dawodu A, Wagner C. Mother-child vitamin D deficiency: an international perspective. Arch Dis Child. 2007:92:737-40.

30. Holick M. The vitamin D epidemic and its health consequences. J Nutr. 2005;35:2739S-48

31. Kensarah OA, Azzeh FS. Vitamin D status of healthy school children from western Saudi Arabia. Pak J Nutr. 2012;3:288.

32. Holick M. Sunlight "D" ilemma: risk of cancer or bone disease and muscle weakness. Lancet. 2001;357:4-6

33. Al Faraj S, Al Mutairi K. Vitamin D deficiency and chronic low back Pain in Saudi Arabia. Spine. 2003:28:177-9.

34. Hobbs RD, Habib Z, Alromaihi D, Idi L, Parikh N, Blocki F, et al. Severe vitamin D deficiency in Arab-American women living in Dearborn. Mich Endocr Pract. 2009;15:35-40.

35. Sedrani SH, Elidrissy AW, El Arabi KM. Sunlight and vitamin D status in normal Saudi subjects. Am J Clin Nutr. 1983;38:129-32.

36. Islam MZ, Akhtaruzzaman M. Hypovitaminosis D is common in both veild and nonveild Bangladeshi women. Asia Pac Clin Nut. 2006;15:81-7.

\section{Submit your next manuscript to BioMed Central and take full advantage of:}

- Convenient online submission

- Thorough peer review

- No space constraints or color figure charges

- Immediate publication on acceptance

- Inclusion in PubMed, CAS, Scopus and Google Scholar

- Research which is freely available for redistribution

Submit your manuscript at www.biomedcentral.com/submit 